\title{
Blood flow restriction: how does it work?
}

\author{
Jeremy P. Loenneke ${ }^{1}$, Takashi Abe ${ }^{2}$, Jacob M. Wilson ${ }^{3}$, Carlos Ugrinowitsch ${ }^{4}$ and Michael G. Bemben ${ }^{1}$ \\ 1 Neuromuscular Research Laboratory, Department of Health and Exercise Science, The University of Oklahoma, Norman, OK, USA \\ 2 Department of Health, Exercise Science, and Recreation Management, University of Mississippi, Oxford, MS, USA \\ ${ }^{3}$ Department of Health Sciences and Human Performance, University of Tampa, Tampa, FL, USA \\ ${ }^{4}$ School of Physical Education and Sport, University of São Paulo, São Paulo, Brazil \\ *Correspondence: jploenneke@ou.edu
}

Edited by:

Marcas Bamman, University of Alabama at Birmingham, USA

Reviewed by:

Marcas Bamman, University of Alabama at Birmingham, USA

The purpose of this viewpoint is to provide rationale for the cellular investigation of blood flow restriction (BFR) in the absence of exercise, as this may provide a novel insight into the mechanisms exclusive to the restriction stimulus itself. Most of the research on BFR thus far has been completed with BFR in combination with low intensity resistance training. To illustrate, BFR in combination with low intensity exercise has consistently been observed to result in improvements in muscle size and function (Loenneke et al., 2012b). However, there is also evidence suggesting that BFR in the absence of exercise results in favorable muscular adaptations (Takarada et al., 2000a; Kubota et al., 2008; Kubota et al., 2011). Despite favorable effects of BFR in the absence of exercise, minimal mechanistic research exists on the BFR stimulus itself. In contrast, several mechanistic studies have been completed with BFR in combination with resistance training. To illustrate, previous research indicates that BFR combined with resistance exercise stimulates muscle protein synthesis (MPS; Fujita et al., 2007; Fry et al., 2010; Gundermann et al., 2012), although little is known about the exact cellular mechanisms associated with these changes in protein balance. It has been suggested that low intensity resistance exercise combined with BFR produces a metabolic "overload" (i.e., depletion of phosphocreatine stores and decreases in muscle $\mathrm{pH}$ ) normally associated with higher muscle activations observed during high intensity resistance exercise (Takarada et al., 2000b; Suga et al., 2010). In addition, it has been recently observed that the benefits of BFR resistance exercise may, in part, be related to the concomitant decrease in the mRNA gene expression of MURF-1, atrogin, and myostatin (Manini et al., 2011; Laurentino et al., 2012).
Three separate investigations have noted positive results from the application of BFR in the absence of exercise. For example, Takarada et al. (2000a) observed that applying BFR $(238 \mathrm{mmHg}, 9 \mathrm{~cm}$ wide cuff) to patients following anterior cruciate ligament reconstruction surgery effectively diminished the post operation disuse atrophy (measured by MRI) of the knee extensors. In support of this attenuating effect, Kubota et al. (2008) found that applying BFR (200 mmHg, $7.7 \mathrm{~cm}$ wide cuff) to a cast immobilized limb not only attenuates decreases in muscle size (measured by leg circumference) but also muscle strength. However, a separate study from the same group indicated that a lower pressure of $50 \mathrm{mmHg}$ reduced muscular weakness induced by chronic unloading, but had no effect on attenuating changes in leg size (Kubota et al., 2011). Interestingly, despite the published evidence, there has been no speculation on what mechanism(s) may be at work during BFR in the absence of an exercise stimulus. Instead, authors have applied the findings from mechanistic work completed on resistance exercise studies to explain results of the aforementioned BFR only studies.

Although reductionism plays an important and useful role in science, there are numerous problems with using this approach to mechanistically understand the effects of BFR in the absence of exercise. For example, the increases in electromyography (EMG) activity observed with low intensity resistance exercise combined with BFR are greater than those observed with resistance exercise alone (Takarada et al., 2000b; Yasuda et al., 2009). One investigation found that the EMG activity was $40 \%$ lower when exercise was completed without BFR (Takarada et al., 2000b). Using the aforementioned reasoning would lead one to suggest that part of the benefits observed with BFR in the absence of exercise are due to this increase in EMG activity, however, in the absence of muscle contraction, there are no changes in EMG activity. Furthermore, our unpublished data also suggests that no measurable changes occur in whole blood lactate, indicating that large changes in hydrogen ion concentration are likely not occurring with BFR in the absence of exercise. The only two variables investigated that did change with BFR only were acute increases in real-time ultrasound measured muscle thickness and a decrease in hematocrit determined plasma volume. These changes were maintained following the removal of the cuff suggesting that the acute changes in muscle thickness were actual acute increases in muscle size (i.e., muscle swelling) and were not attributed to venous pooling. This acute change in size has also been observed following low intensity BFR resistance training. To illustrate, Fry et al. (2010) observed greater acute increases in muscle size (measured by circumference) with BFR resistance exercise compared to resistance exercise without BFR. Interestingly, they too suggest that this might mechanistically explain part of the increase in MPS they observed following BFR resistance exercise.

Many hypotheses exist for the mechanism behind the beneficial effects observed with BFR; however it may be necessary to research the effects of BFR in the absence of resistance exercise in order to allow for a clearer picture of what is physiologically occurring with the BFR stimulus itself. We would like to suggest that acute muscle swelling may be the mechanism behind the reductions in muscle size and strength declines observed following surgery or cast 
immobilization. In addition, this swelling may also help explain the increases in muscle size and strength previously observed from slow walking in combination with BFR (Abe et al., 2006; Ozaki et al., 2011). Although we have non-invasive data suggesting this is true, we are left to speculate as to how the acute increase in muscle size happens and how this acute increase in muscle size might lead to favorable changes in protein balance. Previous findings suggest that cellular dehydration may be involved in the down regulation of mammalian target of rapamycin (mTOR) signaling (Schliess et al., 2006). Therefore, if BFR can acutely increase the influx of water into the muscle cell, this may provide a stimulus capable of stimulating the mTOR pathway. It is acknowledged that this swelling hypothesis is largely dependent on research completed on hepatocytes (Loenneke et al., 2012a); therefore it is unknown how well this mechanism may translate over to human skeletal muscle. Future cellular research should attempt to determine whether or not muscle swelling plays a significant role in the muscle hypertrophic signaling response in humans, which would have important clinical implications for populations contraindicated to exercise.

\section{REFERENCES}

Abe, T., Kearns, C. F., and Sato, Y. (2006). Muscle size and strength are increased following walk training with restricted venous blood flow from the leg muscle, Kaatsu-walk training. J. Appl. Physiol. 100, 1460-1466.
Fry, C. S., Glynn, E. L., Drummond, M. J., Timmerman, K. L., Fujita, S., Abe, T., et al. (2010). Blood flow restriction exercise stimulates $\mathrm{mTORC1}$ signaling and muscle protein synthesis in older men. J. Appl. Physiol. 108, 1199-1209.

Fujita, S., Abe, T., Drummond, M. J., Cadenas, J. G., Dreyer, H. C., Sato, Y., et al. (2007). Blood flow restriction during low-intensity resistance exercise increases S6K1 phosphorylation and muscle protein synthesis. J. Appl. Physiol. 103, 903-910.

Gundermann, D. M., Fry, C. S., Dickinson, J. M., Walker, D. K., Timmerman, K. L., Drummond, M. J., et al (2012). Reactive hyperemia is not responsible for stimulating muscle protein synthesis following blood flow restriction exercise. J. Appl. Physiol. 112, 1520-1528.

Kubota, A., Sakuraba, K., Koh, S., Ogura, Y., and Tamura, Y. (2011). Blood flow restriction by low compressive force prevents disuse muscular weakness. J. Sci. Med. Sport. 14, 95-99.

Kubota, A., Sakuraba, K., Sawaki, K., Sumide, T., and Tamura, Y. (2008). Prevention of disuse muscular weakness by restriction of blood flow. Med. Sci. Sports Exerc. 40, 529-534.

Laurentino, G. C., Ugrinowitsch, C., Roschel,H.,Aoki,M S., Soares, A. G., Neves, M. Jr. et al. (2012). Strength training with blood flow restriction diminishes myostatin gene expression. Med. Sci. Sports Exerc. 44, 406-412.

Loenneke, J. P., Fahs, C. A., Rossow, L. M., Abe, T., and Bemben, M. G. (2012a). The anabolic benefits of venous blood flow restriction training may be induced by muscle cell swelling. Med. Hypotheses 78, 151-154. Loenneke, J. P., Wilson, J. M., Marin, P. J., Zourdos, M. C., and Bemben, M. G. (2012b). Low intensity blood flow restriction training: a meta-analysis. Eur. J. Appl. Physiol. 112, 1849-1859.

Manini, T. M., Vincent, K. R., Leeuwenburgh, C. L., Lees, H. A., Kavazis, A. N., Borst, S. E., et al. (2011). Myogenic and proteolytic mRNA expression following blood flow restricted exercise. Acta Physiol. (Oxf.) 201, 255-263.
Ozaki, H., Sakamaki, M., Yasuda, T., Fujita, S., Ogasawara, R., Sugaya, M., et al. (2011). Increases in thigh muscle volume and strength by walk training with leg blood flow reduction in older participants. J. Gerontol. A Biol. Sci. Med. Sci. 66, 257-263.

Schliess, F., Richter, L., Vom Dahl, S., and Haussinger, D. (2006). Cell hydration and mTOR-dependent signalling. Acta Physiol. (Oxf.) 187, 223-229.

Suga, T., Okita, K., Morita, N., Yokota, T., Hirabayashi, K., Horiuchi, M., et al. (2010). Dose effect on intramuscular metabolic stress during low-intensity resistance exercise with blood flow restriction. J. Appl. Physiol. 108, 1563-1567.

Takarada, Y., Takazawa, H., and Ishii, N. (2000a). Applications of vascular occlusion diminish disuse atrophy of knee extensor muscles. Med. Sci. Sports Exerc. 32, 2035-2039.

Takarada, Y., Takazawa, H., Sato, Y., Takebayashi, S. Tanaka, Y., and Ishii, N. (2000b). Effects of resistance exercise combined with moderate vascular occlusion on muscular function in humans. J. Appl. Physiol. 88 , 2097-2106.

Yasuda, T., Brechue, W. F., Fujita, T., Shirakawa, J., Sato, Y., and Abe, T. (2009). Muscle activation during lowintensity muscle contractions with restricted blood flow. J. Sports Sci. 27, 479-489.

Received: 16 July 2012; accepted: 13 September 2012; published online: 04 October 2012.

Citation: Loenneke JP, Abe T, Wilson JM, Ugrinowitsch $C$ and Bemben MG (2012) Blood flow restriction: how does it work? Front. Physio. 3:392. doi: 10.3389/ fphys.2012.00392

This article was submitted to Frontiers in Striated Muscle Physiology, a specialty of Frontiers in Physiology. Copyright (C) 2012 Loenneke, Abe, Wilson, Ugrinowitsch and Bemben. This is an open-access article distributed under the terms of the Creative Commons Attribution License, which permits use, distribution and reproduction in other forums, provided the original authors and source are credited and subject to any copyright notices concerning any third-party graphics etc. 